\title{
Técnicas de remoção de metais de águas residuárias: uma revisão de literatura
}

\author{
Metals removal techniques from wastewater: a literature review \\ Técnicas de eliminación de metales de aguas residuales: una revisión de la literatura
}

Recebido: 24/01/2022 | Revisado: 28/01/2022 | Aceito: 02/02/2022 | Publicado: 04/02/2022

João Marcos Dos Reis

ORCID: https://orcid.org/0000-0002-1677-4508 Universidade Federal de Alfenas, Brasil E-mail: eng.jmarcosreis@gmail.com

Ana Beatriz Soares Aguiar

ORCID: https://orcid.org/0000-0001-9615-1484 Universidade Federal de Alfenas, Brasil E-mail: beatrizsoaresag@gmail.com

Gabriel Freitas

ORCID: https://orcid.org/0000-0001-9259-3648 Universidade Federal de Alfenas, Brasil E-mail: gabrielfreitasmb@gmail.com

Vitor Chinatto Vassoler

ORCID: https://orcid.org/0000-0002-6094-4383 Universidade Federal de Alfenas, Brasil

E-mail: vassolervitor@gmail.com

Gabriela Vaz Lobo Barros

ORCID: https://orcid.org/0000-0003-0188-3178 Universidade Federal de Alfenas, Brasil

E-mail: gabrielavazlobo.unifal@gmail.com

Gabriela Espirito Santos

ORCID: https://orcid.org/0000-0001-5392-1573 Universidade Federal de Alfenas, Brasil

E-mail: gabrielaespiritosantos56@gmail.com

Irina Ramirez

ORCID: https://orcid.org/0000-0003-2640-3599 Universidad Nacional Toribio Rodriguez de Mendoza, Peru E-mail: indiraramas@gmail.com

Renata Piacentini Rodriguez

ORCID: https://orcid.org/0000-0002-2837-3437

Universidade de São Paulo, Brasil

E-mail: renataprodriguez@gmail.com

\begin{abstract}
Resumo
Devido ao crescimento das indústrias, a geração de efluentes com metais cresce acentuadamente, gerando prejuízos sobre a fauna e flora. A preocupação com o destino dos metais gerados levou ao desenvolvimento de métodos de remoção de poluentes das águas residuárias. O presente estudo revisa os avanços das técnicas de remoção nos últimos anos. Neste trabalho, a remoção de metais foi avaliada sob a ótica dos processos de adsorção (componentes da fase fluida são transferidos para a superfície ou poros de uma fase sólida removendo assim as moléculas de adsorvato), biossorção (ligação de íons das moléculas em solução que se ligam a grupos funcionais presentes na superfície), eletrodiálise (transporte de íons através de membranas de troca iônica através de uma diferença de potencial elétrico como força motriz), osmose reversa (uma membrana é projetada para permitir a passagem da água, enquanto retém solutos), ultrafiltração (separação de íons metálicos por um processo de filtração em uma membrana), precipitação química (combinação de adição de agente coagulante seguida de ajuste do $\mathrm{pH}$ ), precipitação por sulfeto (utilização do sulfeto como precipitador dos íons metálicos presentes), biomineração (microrganismos facilitam extração e recuperação de metais) e biolixiviação (solubilização de metais e reciclagem dada a ação de micro-organismos oxidantes).
\end{abstract}

Palavras-chave: Efluentes contendo metais; Técnicas de tratamento; Revisão.

\begin{abstract}
Due to the growth of the industries, the generation of effluents with metals grows sharply, generating losses on the fauna and flora. Concern about the fate of the metals generated led to the development of methods for removing pollutants from wastewater. The present study reviews the advances in removal techniques in recent years. In this work, the removal of metals was evaluated from the perspective of the adsorption processes (components of the fluid phase are transferred to the surface or pores of a solid phase, thus removing the adsorbate molecules), biosorption (ion binding of the molecules in solution that bind to functional groups present on the surface), electrodialysis (transport of
\end{abstract}


ions through ion exchange membranes through a difference in electrical potential as a driving force), reverse osmosis (a membrane is designed to allow water to pass through, while retaining solutes ), ultrafiltration (separation of metal ions by a membrane filtration process), chemical precipitation (combination of addition of coagulant followed by $\mathrm{pH}$ adjustment), precipitation by sulphide (use of the sulphide as a precipitant of the metal ions present), biomineration (microorganisms facilitate extraction and recovery of metals) and bioleaching (solubilization of metals and recycling due to the action of oxidizing microorganisms).

Keywords: Effluents with metals; Treatment techniques; Review.

\section{Resumen}

Debido al crecimiento de las industrias, crece considerablemente la generación de efluentes con metales, ocasionando daños a la fauna y flora. La preocupación por el destino de los metales generados ha llevado al desarrollo de métodos para eliminar los contaminantes de las aguas residuales. El presente estudio revisa los avances en las técnicas de remoción en los últimos años. En este trabajo se evaluó la remoción de metales desde la perspectiva de procesos de adsorción (los componentes de la fase fluida son transferidos a la superficie o poros de una fase sólida, removiendo así las moléculas de adsorbato), biosorción (unión de iones de las moléculas en solución que se unen a los grupos funcionales presentes en la superficie), electrodiálisis (transporte de iones a través de membranas de intercambio iónico a través de una diferencia de potencial eléctrico como fuerza motriz), ósmosis inversa (una membrana está diseñada para permitir el paso del agua mientras retiene los solutos), ultrafiltración ( separación de iones metálicos mediante un proceso de filtración de membrana), precipitación química (combinación de la adición de un agente coagulante seguido de ajuste de $\mathrm{pH}$ ), precipitación de sulfuro (usando sulfuro como precipitador de los iones metálicos presentes), biominería (los microorganismos facilitan la extracción y recuperación de metales) y biolixiviación (solubilización de metales y reciclado dada la acción de micro-organismos oxidantes).

Palabras clave: Efluentes con metales; Técnicas de tratamiento; Revisión.

\section{Introdução}

Nos dias de hoje, o crescimento populacional associado ao desenvolvimento tecnológico tem se mostrado grande relevância em diversos setores das indústrias, onde o meio ambiente está diretamente relacionado e vem conquistando prestígio no mundo moderno. A degradação ambiental ocasionada por esses fatores fez com que os seres humanos encarassem a natureza como algo que, embora amplo, pode ser degradado e torna-se impróprio para muitas formas de vida (Al Duda \& Ward, 1995).

Diante desse cenário podemos apontar a industrialização como principal fator responsável pelo aumento dos níveis de diversos poluentes. Dentre elas podemos destacar setores de pesticidas, petróleo, farmacêuticas entre outras. Esses tipos de efluentes descartados diretamente no ambiente, é composto de diversas substâncias toxicas muito nocivas ao ser humano, podendo causar doenças graves e contaminado vários tipos de ambientes como a vida aquática, causando a mortandade de seres-vivos da região afetada.

Entre os poluentes presentes em efluentes industriais, os metais pesados, também conhecidos como metais tóxicos, anteriormente assim denominados por serem mais densos que os demais. Outro critério que os define é o fato de serem bioacumulativos, ou seja, se acumulam na cadeia alimentar (plantas e animais) e, consequentemente, no homem. Chumbo, mercúrio, cádmio, cromo, cobre, e arsênio são exemplos dos mais tóxicos e cancerígenos que podem existir em efluentes. Os metais não são facilmente eliminados do corpo humano ocasionando doenças ou envenenamento por metais (Lesmana et al., 2009).

Além dos metais, ocupam lugar de destaque nas preocupações ambientais, os chamados "elementos de terras raras", que receberam esse nome porque seus óxidos insolúveis apresentavam aspecto terroso e como seu estudo foi realizado no final do século dezoito eram considerados raros. No entanto, atualmente sabe-se que se encontram amplamente distribuídos na crosta terrestre, porém em pequenas concentrações, e em diversos minerais (Abrão, 1994).

As tecnologias atuais para mineração e beneficiamento de terras raras produzem impactos ambientais severos sobre o meio ambiente, como emissões para a atmosfera e infiltração de rejeitos para águas subterrâneas, tendo grande impacto social sobre os moradores locais. Essa "pegada ecológica", muito distante dos usos finais "limpos", tem crescido significativamente 
nos últimos anos com o aumento e concentração da produção. (Guimarães, 2011)

Esses elementos são de grande importância uma vez que, depois de separados e purificados, podem ser reutilizados em diversas aplicações, visando assim a valorização dos minerais e dos lucros.

As principais aplicações dos compostos de terras raras no Brasil atualmente são: composição e polimentos de vidros e lentes especiais, catalisadores de automóveis, refino de petróleo, fósforo para tubos catódicos de televisores, ímãs permanentes para motores miniaturizados, ressonância magnética nuclear, cristais geradores de laser, supercondutores e absorvedores de hidrogênio (Andrade, 2011).

$\mathrm{O}$ tratamento adequado de efluentes contendo metais apresenta, além de exigência ambiental, um adicional econômico de alta relevância, tendo em vista que um grande número dos metais possui elevado valor agregado e são de grande interesse do ponto de vista econômico.

Dentro deste contexto, inúmeras técnicas de remoção de metais em efluentes têm sido desenvolvidas, sendo os principais processos: adsorção, biossorção, eletrodiálise, osmose reversa, ultrafiltração, precipitação química, precipitação por sulfeto, biomineração e biolixiviação. O objetivo deste trabalho é revisar as técnicas mais utilizadas em processos de remoção de metais, bem como avaliar questões relativas à eficiência e aplicação das mesmas em escala plena.

\section{Metodologia}

Para a realização do levantamento teórico foi realizada uma revisão sistemática utilizando as bases de dados Scielo, Google Scholar e Web of Science, sendo selecionados os trabalhos acadêmicos que apresentaram objetivos pertinentes ao tema da revisão de literatura. Em um primeiro momento foram levantadas as questões e as lacunas existentes quanto às técnicas de remoção de metais de águas residuárias. E, posteriormente, para a seleção dos artigos foram utilizados os termos indexados: tratamento de efluentes, efluentes com metais e águas residuárias.

Segundo Roever (2017) a revisão sistemática é caracterizada pelas etapas de pesquisa, seleção, avaliação, síntese e relato das evidências científicas que já foram previamente discutidas. Acrescenta-se ainda, que essa metodologia é considerada menos tendenciosa para avaliação e respostas de lacunas encontradas dentro do objeto de pesquisa. Nesse sentido, o presente estudo seguiu os processos citados abaixo para a seleção dos artigos que o compõe:

a) Seleção dos artigos: Em um primeiro momento foram selecionados artigos nas bases de dados supracitadas e que apresentavam palavras-chave semelhantes aos termos indexados durante a busca. Posteriormente, a seleção baseou-se em uma leitura avaliativa, buscando informações que preenchessem as questões acerca da temática;

b) Critérios de inclusão: Após a escolha do tema, foram selecionados os artigos que, dentro do objetivo proposto, respondiam as questões do trabalho, bem como apresentavam discussões relevantes ao objeto de pesquisa;

c) Critérios de exclusão: Artigos que, após a leitura, não apresentaram discussões e/ou argumentos pertinentes ao tema, de forma que não agregariam informações relevantes ao trabalho;

d) Análise e síntese dos dados: Uma vez selecionado os artigos e demais trabalhos acadêmicos que compuseram a presente revisão de literatura, as informações e discussões propostas foram analisadas e sintetizadas, de forma que o texto apresentasse coesão e facilidade de entendimento, ao mesmo tempo em que propõe novas visões relacionadas às técnicas de remoção de metais de águas residuárias.

\section{Resultados e Discussão}

\section{Adsorção}

A adsorção é uma das técnicas mais eficazes e econômicas para o tratamento de efluentes com presença de metais. $\mathrm{O}$ processo de adsorção é versátil, possui projeto simples, operação flexível, os adsorventes utilizados podem ser recuperados, e, 
na maioria dos casos, consegue-se obter uma água residual tratada e de alta qualidade (Fu \& Wang, 2011). No processo de adsorção, componentes de uma fase fluida (adsorvato- metal) são transferidos para a superfície ou poros de uma fase sólida (adsorvente), removendo assim as moléculas de adsorvato da solução aquosa (Burakov et al., 2018).

Vários fatores influenciam no comportamento e desempenho da adsorção na remoção de metais: as características físicas e químicas do adsorvente e do adsorvato, por exemplo, composição, estrutura, tipos de grupos funcionais que estão presentes na molécula e tamanho da partícula. Além disso, outros fatores de influência são o tipo de processo de adsorção e as condições para o seu funcionamento, tais como: $\mathrm{pH}$, temperatura e a velocidade de agitação, sendo que geralmente a taxa de adsorção de metais aumenta com o aumento dos fatores descritos acima (Bisht \& Agarwal, 2016).O tipo de adsorvente utilizado também influencia na remoção de metais, sendo os adsorventes mais utilizados comercialmente o carvão ativado, zeólitas, sílica gel e alumina ativada, devido às suas elevadas áreas superficiais. O carvão ativado tem sido mais empregado devido às suas características de elevada área superficial e grande estrutura porosa. Entretanto, seu custo é alto, o que tem motivado a busca por adsorventes mais baratos, tais como: materiais biológicos e subprodutos agrícolas (Rosenberg, 2015).

Trabalhos sobre adsorção para tratamento de efluentes contendo metais estão sendo desenvolvidos, combinando diferentes adsorventes para remoção de metais, bem como condições operacionais distintas (Khulbe \& Matsuura; 2018; Barakat, 2011; Renu et al., 2016).

A razão adsorvente/adsorvato, bem como o tempo de contato foi avaliado em função da concentração dos adsorventes utilizados (areia, sílica, carvão e alumina) na remoção de um efluente. A alumina foi o adsorvente que apresentou a maior eficiência na remoção de $\mathrm{Cr}, \mathrm{Pb}, \mathrm{Ni}, \mathrm{Cd}, \mathrm{Cu}$ e $\mathrm{Zn}$ com uma média de remoção de cerca de $80 \%$ para 4 g/L de metais adicionados inicialmente e um tempo de adsorção de 5 min (Josefa et al., 2003).

Hu et al. (2009) estudaram a remoção de Cr(VI) utilizando nanotubos de carbono e a remoção máxima de $100 \%$ foi atingida quando se utilizou $\mathrm{pH}$ 2, sendo que a remoção de $\mathrm{Cr}$ (VI) diminuiu com o aumento dos valores de $\mathrm{pH}$ até adsorção nula em pH> 6 (HU et al., 2009). Já para a adsorção do Pb (II). Wang et al. (2007) relataram que utilizando como adsorvente nanotubos de carbono acidificados, os grupos funcionais oxigenados presentes na molécula do adsorvente foram responsáveis por permitir a adsorção de $\mathrm{Pb}$ (II) em até $75,3 \%$.

\section{Biossorção}

Os estudos voltados para o processo de biossorção como tratamento para remoção de metais estão sendo desenvolvidos há alguns anos, como por exemplo o trabalho publicado por Strandberg et al. (1981), o qual estudou técnicas de biossorção de urânio, metal com alto nível de toxidade, em sua pesquisa foram analisados o desempenho dos microrganismos Saccharomyces cerevisiae e uma cepa de Pseudomonas aeruginosa como biossorventes. Atualmente, desenvolveram-se inúmeras propostas com base na capacidade de remoção de compostos tóxicos, como metais, de soluções aquosas a partir do uso de sorventes biológicos.

O método de biossorção é uma proposta promissora devido ao seu baixo custo e alta eficiência na remoção de compostos poluentes. Além disso, o processo apresenta outras vantagens, como uma menor quantidade requerida de biossorvente, menor produção de biomassa destinada à um tratamento final e possibilidade de atuar em um sistema sem alimentação de nutrientes (He \& Chen, 2014).

O processo de biossorção de metais ocorre de forma rápida através da ligação dos íons metálicos em solução aos grupos funcionais presentes na superfície do biossorvente, sendo, portanto, uma ligação reversível e independente do metabolismo celular. Por isso, um biossorvente é selecionado devido a presença de grupos funcionais que são capazes de ligar às substâncias poluentes. Os principais grupos funcionais responsáveis pela adesão de compostos tóxicos, como os metais, são, os grupos carboxila, sulfato, fosfato, hidroxila e amina. Além disso, existem outros parâmetros que influenciam diretamente o sistema 
como, $\mathrm{pH}$, temperatura, tamanho da partícula de biossorvente e o estado de equilíbrio do meio (He \& Chen, 2014; Michalak et al., 2013).

Dentre os tipos de biossorventes mais utilizados para remoção e recuperação de íons metálicos encontram-se bactérias, cianobactérias, algas, leveduras, fungos e líquenes devido ao baixo custo e elevada disponibilidade. Além deles, existem outros biomateriais que têm sido estudados, como casca de coco, casca de plantas, folhas, serragem, bagaço de cana e turfa (Michalak et al., 2013).

Os biossorventes podem ser classificados como biomassa ativa ou inativa. Alguns estudos identificaram que os biossorventes derivados de uma biomassa inativa podem ser mais eficientes do que aqueles derivados de uma biomassa ativa, visto que, no primeiro caso, não há necessidade de disponibilizar nutrientes para o desenvolvimento dos microrganismos. Em alguns casos, quando se utilizam biossorventes inativos é necessário realizar a imobilização do mesmo para otimizar o contato do material com o meio, o que também confere melhorias nas condições de resistência mecânica. E para otimizar o contato da área superficial do biossorvente com o material a ser removido, a biomassa seca pode ser triturada, resultando em partículas menores e mais estáveis (He \& Chen, 2014; Michalak et al., 2013).

Alguns autores classificam o processo de biossorção de acordo com a localização do metal após o tratamento, sendo eles: biossorção intracelular; biossorção na superfície celular; e precipitação extracelular. Quando ocorre a biossorção intracelular, o processo é dependente do metabolismo microbiano, pois ele é resultante do transporte de metais por meio da membrana celular do biossorvente. No caso da biossorção na superfície celular, o processo consiste em uma interação físicoquímica que liga os íons metálicos a superfície celular, não dependendo significativamente do metabolismo celular. No último caso, a biossorção ou precipitação extracelular ocorre quando a captação do metal é evidenciada entre a superfície celular e a solução. Em alguns casos esse tipo de biossorção pode ou não ser dependente do metabolismo microbiano. Essa dependência ocorre quando os microrganismos são responsáveis pela produção de compostos que favorecem a precipitação dos metais (De Freitas et al., 2019).

Hadiani et al. (2018) estudou a eficiência de remoção dos íons Pb (II) e Cd (II) em baixas concentrações em soluções aquosas utilizando como biossorvente um fungo da espécie Saccharomyces cerevisiae. Para avaliar o potencial de descontaminação, os autores trabalharam com diferentes variáveis de processo, como concentração de biossorvente e íons metálicos, $\mathrm{pH}$ da solução, temperatura, tempo, viabilidade da biomassa e agitação. Os resultados obtidos no trabalho alcançaram uma taxa média de biossorção para o $\mathrm{Pb}$ (II) de 70,7\% e para o Cd (II) de 76,9\%, indicando elevada afinidade do microrganismo Saccharomyces cerevisiae pelos íons metálicos. Em relação ao efeito do pH do meio, notou-se que a eficiência da biossorção foi melhor no $\mathrm{pH}$ 5. Em pH menor ou maior, observou-se uma queda no potencial de remoção dos contaminantes, sendo essa variável um fator importante para o desempenho do sistema, pois ele interfere diretamente na ionização dos grupos funcionais disponíveis na parede celular. Ainda nesse estudo, os autores observaram que a biossorção dos metais aumentou com o aumento da concentração dos íons $\mathrm{Pb}$ e $\mathrm{Cd}$ na solução, sendo que a concentração ótima encontrada neste trabalho foi de 52,5 $\mu \mathrm{g} / \mathrm{L}$. Porém, o aumento da concentração da biomassa diminuiu a eficiência da biossorção, sendo que a biossorção máxima ocorreu em uma concentração de $32,5 \times 10^{7} \mathrm{UFC} / \mathrm{g}$.

A remoção dos íons $\mathrm{Pb}, \mathrm{Cu}$ e Cd através do processo de biossorção foi avaliada utilizando como biomassa um conjunto de bactérias denominadas de Pseudomonas aeruginosa. Nesse caso, observou-se um melhor potencial de adsorção em valores de $\mathrm{pH}$ maiores, visto que quando o pH diminui, a concentração de íons $\mathrm{H}^{+}$aumenta, tornando a superfície celular carregada positivamente, e, diminuindo assim a atração da biomassa pelos íons metálicos. Além disso, a biomassa mostrou-se mais eficiente para remoção de chumbo, visto que cobre e cádmio foram removidos em menores proporções (Chang et al., 1997).

Shokoohi et al. (2009) estudou a influência da concentração de íons de ferro no processo de biossorção, assim como a influência do tempo de contato do íon metálico com o biossorvente. A biomassa do sistema foi derivada de um sistema de lodo 
ativado e posteriormente inativada, por meio de um processo de secagem. Analisando a concentração inicial de ferro na solução, notou-se um declínio na eficiência do processo de biossorção com o aumento da concentração do íon metálico, entre 2 a $10 \mathrm{mg} / \mathrm{L}$, e esse aumento ocasionou uma redução de $70 \%$ para $56 \%$ na eficiência do processo de remoção. Quando se analisou o tempo de contato do íon metálico em solução com a biomassa, observou-se que o aumento do tempo de contato garantiu melhores eficiência na remoção do ferro de $56 \%$ para $89 \%$, entre $0,5 \mathrm{~h}$ a $2,5 \mathrm{~h}$. A remoção de ferro também foi dependente do aumento de biomassa $(0,1 \mathrm{~g}$ para $0,9 \mathrm{~g})$, com uma eficiência crescente de $62 \%$ para $95 \%$.

\section{Eletrodiálise}

Águas residuais contendo íons metálicos ocorrem com maior frequência à medida que fluxos grandes e concentrações relativamente baixa de íons são separados, o que dificulta a operação das técnicas tradicionais de separação. Assim, a aplicação de técnicas de membrana ao tratamento dessas águas como auxiliar ou substituto dos métodos tradicionais é uma sugestão altamente atraente. A adequação de processos como nanofiltração, osmose reversa e a eletrodiálise são algumas delas (Mohammadi et al., 2005).

A eletrodiálise é uma técnica de eletro membrana que tem vantagens importantes, como o baixo uso de agentes químicos e a alta recuperação de água. A técnica é baseada no transporte de íons através de membranas de troca iônica sob influência de uma diferença de potencial elétrico como força motriz (Gherasim et al., 2014).

A solução ou o resíduo a ser tratado circula através de uma pilha, que consiste em uma série de membranas de troca iônica paralelas e membranas de troca catiônica que são fixadas entre dois eletrodos, o ânodo e o cátodo. Sob uma diferença de potencial entre esses eletrodos, os cátions se movem em direção ao cátodo e os ânions migram para o ânodo, permeando as membranas com carga oposta e sendo retidas pelas membranas de troca iônica com a mesma carga (Gherasim et al., 2014).

Muitos experimentos relatados de remediação eletrodialítica para suspensões agitadas consistem em uma configuração experimental de pelo menos três compartimentos, como podemos ver na representação da Figura 1. Os eletrodos são colocados em compartimentos separados (I e III), onde circulam soluções eletrolíticas. A suspensão agitada localiza-se no compartimento do meio (II) e as membranas de troca iônica (AN - membrana de troca aniônica; CAT - membrana de troca catiônica) separam os compartimentos para restringir a eletromigração através da célula fora do compartimento central (Ebbers et al., 2014).

Uma corrente direta da ordem de alguns mA é aplicada aos eletrodos. As semi-reações eletrolíticas nos eletrodos diminuem o pH próximo ao ânodo e aumentam o pH próximo ao cátodo (Ebbers et al., 2014).

Figura 1 - Compartimentos para a remediação por eletrodiálise

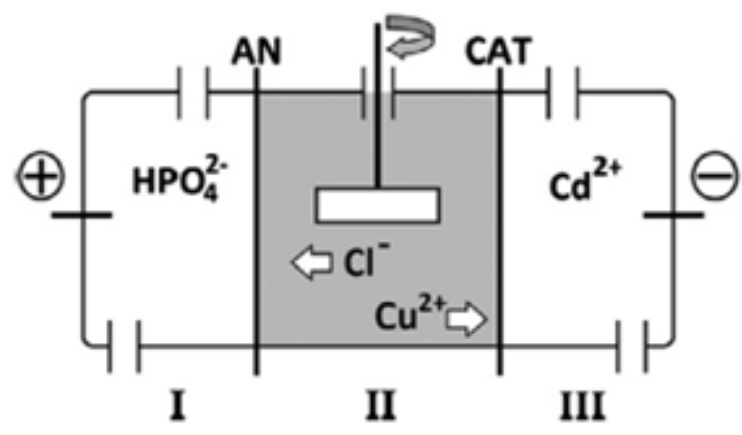

Fonte: Ebbers et al. (2014). 
A eletrodiálise foi desenvolvida pela primeira vez para a dessalinização de soluções. Atualmente, a produção de água potável ainda é a aplicação industrial mais importante da eletrodiálise, mas o uso em tratamento de efluentes industriais está ganhando importância crescente (Mohammadi et al., 2005).

Se tratando especificamente sobre remoção de metais, as técnicas convencionais para redução desses íons metálicos não fornecem eficiência suficiente e, como consequência, são necessários processos de tratamento secundários. Uma técnica importante para o tratamento secundário é a troca iônica, em que os íons metálicos contidos na solução residual são trocados pelos íons menos tóxicos contidos na matriz fixa de um leito de troca iônica. Quando o leito atinge a capacidade, ele é regenerado com um eletrólito concentrado, como um ácido forte. Isso produz um fluxo de resíduos concentrado que deve ser tratado e, finalmente, descartado de maneira devida. Outra técnica é a utilização de sistemas híbridos combinando troca iônica com eletrodiálise que apresentam as vantagens das duas técnicas individuais. Esse tipo de sistema é obtido por inserção de um leito de resina de troca iônica, inicialmente na forma $\mathrm{de}^{+}$, no compartimento central, localizado entre duas membranas seletivas de íons, dividindo assim, a célula em três compartimentos. A solução a ser tratada é injetada continuamente por meio de um leito compactado de resinas de troca iônica. Durante o processo, os cátions metálicos são absorvidos pelas resinas e transportados para o compartimento do cátodo sob a ação do campo elétrico aplicado. A eletrólise da água ocorre nos dois compartimentos externos do eletrodo e o $\mathrm{H}^{+}$formado no ânodo é transferido através da membrana para o leito de resina e substitui os íons metálicos que depois migram através da segunda membrana para o compartimento do eletrodo (Mahmoud et al.,2012).

Gherasim (2014) estudou a remoção de íons Pb (II) utilizando eletrodiálise. O efeito dos parâmetros operacionais no desempenho do processo foi investigado. As condições operacionais ideais para a dessalinização foram assim selecionadas considerando os critérios de obtenção de alta remoção de íons $\mathrm{Pb}$ (II) e a eficiência do processo de eletrodiálise. Verificou-se que uma alta separação de íons $\mathrm{Pb}$ (II) poderia ser obtida por eletrodiálise na faixa de parâmetros investigados. Aumentar a tensão aplicada, a taxa de fluxo e a temperatura do processo aumentou a taxa de transferência de íons através das membranas, mas teve um efeito negativo no consumo de energia. Usando voltagens adequadas e vazão alta o suficiente à temperatura ambiente $\left(25^{\circ} \mathrm{C}\right)$, a eficiência alcançada ficou entre $70-82,8 \%$.

\section{Osmose Reversa}

O objetivo da osmose reversa na separação de metais, sais e outros conteúdos da água, é usar uma membrana seletiva. A membrana é projetada para permitir a passagem da água, enquanto retém os solutos. Quando a água de alimentação é pressurizada, a água pura passa pela membrana na corrente de permeado (Figura 2). A água concentrada que não permeia na membrana deixa o sistema como rejeitos. 
Figura 2 - Princípio do processo de osmose reversa.

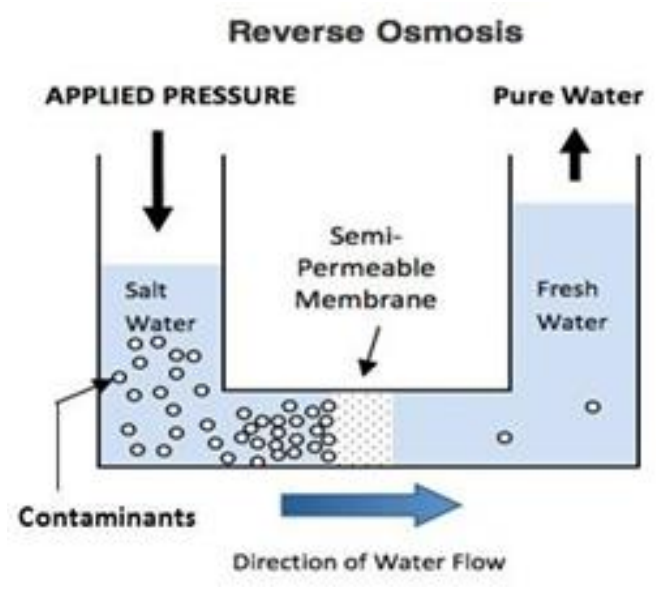

Fonte: Shahalam Am et al. (2002).

Sob pressão operacional de 5 atm, a técnica de osmose reversa pode alcançar 99,5\% de eficiência de remoção de $\mathrm{Cu}^{2+} \mathrm{e}$ $\mathrm{Ni}^{2+}$ (mohsen-nia et al., 2007). Em uma operação a $1100 \mathrm{kPa}$ de pressão, a eficiência de remoção de $\mathrm{Ni}^{2+}$ e $\mathrm{Zn}^{2+}$ obtida foi de 99,3 e 98,9\%, respectivamente (Zhang et al., 2009). Quando a osmose reversa foi combinada com o eletropolimento, o resultado mostrou que a remoção de $\mathrm{Cu}^{2+}$ pode variar de 70 a 95\% (IPEK, 2005).

Os resultados para a remoção de metais usando técnicas de osmose reversa obtidos por Ozaki e Sharma, (2002) estão destacados no Quadro 1.

Quadro 1: Resultados de estudos experimentais sobre remoção de metais pesados utilizando tratamentos por osmose reversa.

\begin{tabular}{|l|l|l|l|l|}
\hline Metal & $\begin{array}{l}\text { Concentração inicial do metal [mg } \\
\left.\mathbf{L}^{-1}\right]\end{array}$ & Pressão [bar] & pH & Remoção [\%] \\
\hline $\mathrm{Ni}$ & 50 & 100 & N.A & 97.3 \\
\hline $\mathrm{Cu}$ & 50 & 100 & N.A & 97.4 \\
\hline $\mathrm{Cr}$ & 50 & 100 & N.A & 98.3 \\
\hline $\mathrm{Ni}$ & 50 & 500 & N.A & 99.5 \\
\hline $\mathrm{Cu}$ & 50 & 500 & N.A & 99.6 \\
\hline $\mathrm{Cr}$ & 50 & 500 & N.A & 100 \\
\hline $\mathrm{Ni}$ & 50 & 3.5 & 3 & 98.88 \\
\hline $\mathrm{Cu}$ & 50 & 3.5 & 3 & 98.83 \\
\hline $\mathrm{Cr}$ & 50 & 3.5 & 3 & 99.01 \\
\hline $\mathrm{Ni}$ & 50 & 3.5 & 9 & 99.9 \\
\hline $\mathrm{Cu}$ & 50 & 3.5 & 9 & $>99.9$ \\
\hline $\mathrm{Cr}$ & 50 & 3.5 & 9 & $>99.9$ \\
\hline
\end{tabular}

*N.A: Não se aplica. Fonte: Adaptação de Ozaki e Sharma (2002).

As vantagens da remoção de metais usando osmose reversa incluem (Shahalam Am, Al-Harthya \& Al-Zawhry, 2002): custos operacionais e de energia medianos; amolecimento da água dura; remoção de metais, sais e outros íons em uma grande porcentagem; não requer adição de produtos químicos; não promove alteração do pH e nem mudança de fase; requer equipamento simples; e é eficaz mesmo em baixas concentrações. 


\section{Ultrafiltração}

O processo de ultrafiltração para remoção de metais consiste em um método de separação de íons metálicos por um processo de filtração em uma membrana de $5 \mathrm{kDa}$ (quilodaltons), onde os mesmos são retidos na membrana-filtro. As técnicas de separação deste processo são consideradas de baixo custo operacional e alta eficiência de remoção.

Bernat (2007) observou que a membrana da cerâmica foi capaz de recuperar espécies de $\mathrm{Fe}$ (II), $\mathrm{Fe}$ (III), $\mathrm{Cu}$ (II) e Cr (III), em soluções aquosas. Os autores construíram um modelo de planta de filtração contínua caseira, de fluxo tangencial com bombas, amortecedor de pulso, manômetro e uma válvula esférica instalada antes da membrana cerâmica. As soluções filtradas eram armazenadas em um pequeno reservatório de 5L. O trabalho constatou que o Fe (III), apresenta maior interação com o material da membrana, uma vez que ele possui mais hidróxidos carregados solúveis, formando assim uma camada sobre a superfície da membrana, o que aumenta a capacidade de retenção dos íons metálicos. Em contrapartida, por não apresentarem hidróxidos carregados solúveis, os íons de Fe (II) não puderam ser retidos na membrana. Já quando os íons são misturados o sistema apresenta filtração eficiente.

Concluíram que a retenção está diretamente ligada à relação a proporção $\mathrm{Fe}(\mathrm{III}) / \mathrm{Fe}(\mathrm{II})$, ema vez que, quanto maior a concentração de hidróxidos, maior a retenção de íons na membrana.

Já para o $\mathrm{Cu}$ (II), a diminuição do fluxo de permeado foi muito baixa, quando comparado com o observado nas soluções contendo Fe (III) e Fe (II). Observou que, por não apresentar hidróxidos carregados, o Cu (II) apresentou baixa retenção.

Dessa forma, esse método é capaz de separar metais pesados através da dimensão dos poros da membrana permeável. No decorrer da passagem de água, os solutos de baixo peso molecular que possuem dimensões maiores que a do tamanho dos poros são retidos na membrana.

\section{Precipitação Química}

O método de precipitação química é muito utilizado na remoção de metais de efluentes, uma vez que é um processo cujas operações de tratamento são simples. Esta técnica consiste em uma combinação da adição de agente coagulante seguida de ajuste do pH. Após a reação química dos íons metálicos dissolvidos no efluente com o agente precipitante, os metais se tornam insolúveis em uma fase sólida. O metal agora na forma de um precipitado na solução se encontra normalmente na forma de hidróxidos ou sulfetos metálicos (Agustiono et al., 2006).

O método de precipitação química mais utilizado é a precipitação com hidróxido, por ser simples, com baixo custo e por apresentar uma maior facilidade no controle do pH. O pH ideal para o processo de precipitação é na faixa de 8,0-11,0. Vários tipos de hidróxidos têm sido usados na remoção de metais, porém devido a facilidade em manusear e pelo baixo custo, a cal $(\mathrm{CaO})$ é, ainda, a mais utilizada na indústria para o tratamento de águas residuais (Huisman et al., 2006).

Apesar de sua ampla utilização, a precipitação química possui algumas desvantagens, sendo que a principal delas é que os efluentes tratados não podem ser recirculados por possuírem altos teores de sais dissolvidos, desta forma, aumentando-se os custos com a disposição do lodo produzido e grande quantidade de produtos químicos. Vale ressaltar também que a precipitação ocorre de forma lenta e possui baixo coeficiente de sedimentação (Barakat, 2011).

Inúmeros trabalhos reportaram o uso de precipitação química na remoção de metais (Rozaimah et al., 1999; Baltpurvins, et al., 1997; Pang et al., 2009). Gopalratnam et al. (1988) relataram 80\% de remoção de $\mathrm{Zn}, \mathrm{Cu}$ e Pb de águas residuais industriais associando precipitação de hidróxido e flotação por ar dissolvido. Em outro tratamento, cal foi utilizada para a remoção de metais como Zn (II), Cd (II) e Mn (II), cujas concentrações iniciais eram de 450,150 e 1085 mg/L. Ao término do tratamento, observou-se remoção quase total destes metais do efluente, em condições de pH 11 (Agustiono et al., 2006). 
Outros estudos, utilizando a técnica de precipitação química são apresentados no Quadro 2, na qual para cada remoção de metal, variou se as concentrações iniciais dos metais, os ensaios se realizaram em pH distintos e diferentes agentes precipitantes foram utilizados.

Quadro 2: Remoção de metais utilizando o método de precipitação química.

\begin{tabular}{|l|l|l|l|l|l|}
\hline Metais & $\begin{array}{l}\text { Concentração } \\
\text { Inicial do Metal }\end{array}$ & Precipitante & $\begin{array}{l}\text { pH } \\
\text { ideal }\end{array}$ & $\begin{array}{l}\text { Eficiência de } \\
\text { remoção (\%) }\end{array}$ & Referências \\
\hline $\mathrm{Zn}^{2+}$ & $32 \mathrm{mg} / \mathrm{L}$ & $\mathrm{CaO}$ & $9-10$ & $99-99,3$ & Ghosh; Samanta; Ray, 2011 \\
\hline $\begin{array}{l}\mathrm{Cu}^{2+}, \mathrm{Zn}{ }^{2+}, \\
\mathrm{Cr}^{3+}, \mathrm{Pb}^{2+}\end{array}$ & $100 \mathrm{mg} / \mathrm{L}$ & $\mathrm{CaO}$ & $7-11$ & $99,37-99,6$ & CHEN et al., 2009 \\
\hline $\begin{array}{l}\mathrm{Cu}^{2+}, \mathrm{Zn}^{2+}, \\
\mathrm{Pb}^{2+}\end{array}$ & $0,018,1,34,2,3 \mathrm{mM}$ & $\mathrm{H} 2 \mathrm{~S}$ & 3.0 & $100,>94,>92$ & $\begin{array}{l}\text { Alvarez; Crespo; Mattiasson, } \\
2007\end{array}$ \\
\hline $\mathrm{Cr}^{3+}$ & $5363 \mathrm{mg} / \mathrm{L}$ & $\mathrm{CaO}$ e MgO & 8.0 & $>99$ & Guo et al., 2006 \\
\hline $\mathrm{Hg}^{2+}$ & $65,6,188 \mu \mathrm{g} / \mathrm{L}$ & 1,3 benzenodiamidoetanotiolato & $\begin{array}{l}4.7 \\
6.4\end{array}$ & $>99,9$ & Blue et al., 2008 \\
\hline $\mathrm{Cu}$ EDTA & $25,50,100 \mathrm{mg} / \mathrm{L}$ & $\begin{array}{l}1,3,5- \\
\text { hexahidrotriazioditiocarbamato }\end{array}$ & 3.0 & $99,0-99,6$ & Fu, 2007 \\
\hline
\end{tabular}

Fonte: Autores (2020).

Ghosh et al. (2011) realizaram ensaios utilizando zinco proveniente de água residual com concentração inicial de 32 $\mathrm{mg} / \mathrm{L}$ e utilizando cal $(\mathrm{CaO})$ como agente precipitante, com concentrações variáveis $(0,625 \mathrm{~g} / \mathrm{L}$ a $3,2 \mathrm{~g} / \mathrm{L})$. O pH variou de 8 12. A remoção mais eficiente de zinco $(99-99,3 \%)$ foi obtida na faixa de $\mathrm{pH}$ de 9-10, formando o precipitado de $\mathrm{Zn}(\mathrm{OH})_{2}$ insolúvel, reduzindo a concentração de zinco de 0,32 para $0,2 \mathrm{mg} / \mathrm{L}$. A remoção de zinco aumentou em pH 10 devido à baixa solubilidade do $\mathrm{Zn}(\mathrm{OH})_{2}$ formado. Acima do $\mathrm{pH}$ 10, a remoção diminuiu devido à formação das espécies negativas solúveis predominantes $\mathrm{Zn}(\mathrm{OH})^{3-}$ e $\mathrm{Zn}(\mathrm{OH})_{4}{ }^{-2}$.

Chen et al. (2009) aplicou o método de precipitação química, utilizando cal, com concentração de $900 \mathrm{mg} / \mathrm{L}$ em efluente sintético na presença de $\mathrm{Cu}$ (II), $\mathrm{Cr}$ (III), Pb (II) e Zn (II). As concentrações dos metais: cromo, cobre, chumbo e zinco foram reduzidas para 0,08,0,14, 0,03 e 0,45 mg/L, respectivamente. Obtiveram-se altas eficiências de remoção, em uma ampla faixa de pH (6-12). Para o cobre, em pH 4, ocorreu precipitação de 70\% e em pH 6 a remoção aumentou para 99,31\%. O pH entre 810 favoreceu uma alta remoção de zinco $97 \%$, enquanto $98 \%$ de chumbo foi removido entre os pH 7 e 11 . A faixa de pH ideal para a precipitação de cromo esteve entre 7 a 10.

Guo et al. (2006) estudaram a precipitação do metal $\mathrm{Cr}^{3+}$ com uma concentração de $\mathrm{Cr}{ }^{3+}$ de $3000-6000 \mathrm{mg} / \mathrm{L}$. Primeiramente, testou a precipitação deste metal com $\mathrm{NaOH}$, porém gerou se uma baixa sedimentação do lodo formado. Portanto, substituiu se $\mathrm{NaOH}$ por $\mathrm{CaO}$ ou $\mathrm{MgO}$, tendo como resultado, menor quantidade de lodo e menor tempo de sedimentação, devido ao tipo de ligação que ocorre entre $\mathrm{Cr}^{3+}$ e $\mathrm{CaO}$ ou $\mathrm{MgO} . \mathrm{O} \mathrm{MgO}$ conseguia aumentar a capacidade de pureza e desidratação do lodo. O melhor agente precipitante foi uma mistura de $\mathrm{CaO}$ e $\mathrm{MgO}$, tendo menor custo e maior eficiência.

Blue et al. (2008) relataram a dificuldade de se encontrar precipitantes comerciais que possam ligar de forma irreversivelmente e permanentemente ao mercúrio. O precipitante 1,3-benzenodiamidoetanotiolato foi testado e responsável por reduzir a concentração de mercúrio e produzir um precipitado estável. Neste trabalho, observou-se uma remoção de Hg maior que $99,9 \%$ a um $\mathrm{pH} 4,7$ e 6,4 .

Fu et al. (2007) testou um precipitante novo de metais, 1,3,5-hexahidrotriazioditiocarbamato (HTDC) preparado e usado para remover o cobre das águas residuais. Este tipo de precipitante consegue precipitar o cobre para menos de 0,5 mg/L contendo $\mathrm{Cu}$ EDTA na faixa de $\mathrm{pH} 3-9$. As concentrações residuais de $\mathrm{Cu}^{2+}$ diminuíram à medida que a razão molar de $\mathrm{HTDC}$ 
/ $\mathrm{Cu}$ foi aumentada. As concentrações residuais de $\mathrm{Cu}$ foram de 0,24, 0,33 e 0,40 mg/L para três concentrações de Cu EDTA 25, 50 e 100 mg/L, respectivamente. Obteve-se uma porcentagem de remoção de 99,0 a 99,6, sendo a maior delas em pH 3.

\section{Precipitação por Sulfeto}

A precipitação por sulfeto apresenta-se como uma técnica para o tratamento de efluentes contendo metais, apesar de não ser um método muito aplicado em larga escala, o procedimento pode apresentar algumas vantagens como a baixa solubilidade dos sulfetos metálicos no meio líquido, remoção seletiva de metais e por isso apresenta um bom potencial para recuperação dos metais ligados ao sulfeto (Ye et al., 2017). O fato da precipitação por sulfeto produzir precipitados mais estáveis, como o sulfeto metálico, torna-se uma alternativa mais viável que a precipitação por hidróxido, a qual produz hidróxidos metálicos que podem ser instáveis durante o processo de tratamento (Yan et al., 2017). Contudo, a precipitação do sulfeto tem como desvantagem a dificuldade em controlar a concentração ideal de sulfeto no meio, uma vez que, altas concentrações podem desencadear toxicidade aos microrganismos e corrosividade (Lewis, 2010).

Na técnica de precipitação por sulfeto para o tratamento de águas residuárias com metais, o sulfeto é utilizado como agente precipitante dos íons metálicos presentes no meio. O sulfeto pode ser empregado na solução a partir de compostos químicos, como o sulfeto de sódio $\left(\mathrm{Na}_{2} \mathrm{~S}\right)$ ou a partir do sulfeto biogênico provindo das bactérias redutoras de sulfato (BRS), sendo esse processo limitado pela baixa eficiência de remoção sólido-líquido do lodo. Já foram publicados diversos trabalhos que utilizaram métodos como o de semeadura, coagulação, floculação, separação magnética, entre outras técnicas com intuito de otimizar o desempenho de sedimentação do lodo (Yanet al., 2017).

A eficiência de remoção dos metais $\mathrm{Cu}, \mathrm{Pb}$ e $\mathrm{Cd}$, através da precipitação do sulfeto, foi avaliada na presença dos adsorventes pirita e sulfeto de ferro sintético. Outras variáveis analisadas no processo foram pH, temperatura, tempo de contato, concentração inicial de metal, concentração inicial de adsorvente. Nesse caso, eles observaram que maiores concentrações de adsorventes e menores concentrações de metais no meio tendem a obter remoções mais eficientes do metal. Além disso, notou-se que o pH interfere diretamente na eficiência do processo, sendo pH 6 como o pH ótimo para remoção de $\mathrm{Cu}$ e Cd e o pH 5 para a remoção de $\mathrm{Pb}$ (Ozverdi \& Erdem, 2006).

Uma pesquisa estudou o processo de remoção de metal da drenagem ácida de mina e identificou que inicialmente o processo de adsorção dos metais ocorre, porém há uma competição entre os mesmos pelos os sítios ativos disponíveis, dessa forma no decorrer do processo há a formação de sulfeto e assim a precipitação de sulfetos metálicos se dá em maiores proporções com objetivo de remover os metais presentes em solução (Machemer \& Wildeman, 1992).

A precipitação de sulfetos metálicos também pode ocorrer por via biológica. As bactérias redutoras de sulfato (BRS), em meio anaeróbio, são capazes de reduzir o sulfato a sulfeto e assim promover a precipitação dos metais que serão sedimentados e posteriormente removidos do reator. Janyasuthiwong et al. (2015) obtiveram eficiências de remoção significativas para o $\mathrm{Cu}$ e o $\mathrm{Zn}$, nos $\mathrm{pH} 7$ e 5 operando um biorreator, porém para o Ni o sistema não foi tão eficiente, pois nesse caso havia necessidade de outros íons metálicos e alguns compostos orgânicos fornecidos pela biomassa.

Alvarez; Crespo; Mattiasson (2007) avaliaram a remoção dos metais $\mathrm{Zn}$ (II), Cu (II) e Pb (II) em drenagem ácida de mina, com pH inicial igual a 3. Para remoção destes metais, foi utilizado o sulfeto de hidrogênio, o que resultou em remoção de $100 \%$ para o cobre, entre $94 \%$ e $100 \%$ para o zinco e entre $92 \%$ e $100 \%$ para o chumbo. Observou se que houve uma residual de $\mathrm{H}_{2} \mathrm{~S}$, o que possibilitaria tratar uma maior quantidade de água residuária. Pensando em um ambiente industrial, deve-se adicionar ao processo um sistema de recirculação do efluente após a etapa de precipitação, como forma de aproveitamento do sulfeto que restou no efluente. 


\section{Biomineração}

A biomineração é o processamento de minérios e concentrados contendo metais por meio de tecnologia microbiológica. Tem aplicação como alternativa aos métodos físico-químicos mais tradicionais de processamento de minerais. O uso de microrganismos para facilitar a extração e recuperação de metais preciosos e básicos de minérios primários e concentrados, tornou-se uma área bem-sucedida e em expansão de biotecnologia (Brierley, 2008; Rawlings \& Johnson, 2007).

As pesquisas nessa área começaram em meados da década de 40, com a descoberta da bactéria Acidithiobacillus ferrooxidans e a compreensão inicial do envolvimento desse microrganismo na extração de cobre. Hoje, a biomineração é amplamente praticada comercialmente em todo o mundo para aprimorar a extração de ouro de minérios e concentrados minerais, para extrair cobre de minérios secundários e, numa base mais limitada, para lixiviar metais comuns (Brierley, 2008).

Os microrganismos que catalisam os processos de biomineração devem crescer em um ambiente essencialmente inorgânico, aeróbio e de baixo pH. Os microrganismos mais importantes são, portanto, autotróficos e, embora a natureza exata das fontes de energia possa variar de mineral para mineral, elas crescem oxidando formas reduzidas de enxofre ou ferro. $\mathrm{O} \mathrm{pH}$ dentro de tanques também pode variar, mas é altamente ácido e normalmente dentro da faixa de 1,5 a 2,0 (Rawlings \& Johnson, 2007).

As principais desvantagens da biomineração são o tempo prolongado necessário para obter níveis econômicos de extração de metal, que pode variar entre dias ou até anos e preocupações sobre a robustez e confiabilidade dos sistemas biológicos envolvidos. Por outro lado, a biomineração é geralmente percebida como uma abordagem muito mais benéfica ao ambiente, envolvendo temperaturas muito mais baixas e, portanto, menores custos de energia (Johnson, 2014).

A biomineração é aplicada comercialmente em métodos como a biolixiviação de minérios de baixo teor e a biooxidação de minerais. A biolixiviação geralmente se refere à tecnologia de biomineração aplicada aos metais básicos; enquanto que a biooxidação de minerais é frequentemente aplicada à biomineração de minérios e concentrados de ouro (Brierley, 2008).

\section{Biolixiviação}

A biolixivição também conhecida como bio-hidrometalúrgica é uma tecnologia que consiste na solubilização de metais e posteriormente na sua reciclagem. O método ocorre a partir da ação de micro-organismos oxidantes como Fe e S. Sendo considerada como uma das técnicas mais eficiente em termos de solubilização de metais (Nascimento et al., 2018).

Ela foi desenvolvida recentemente atraindo assim a atenção da comunidade científica por ser uma tecnologia econômica e favorável ao meio ambiente. Segundo Asghari et al. (2013), em comparação com outros métodos convencionais, a biolixiviação é uma tecnologia ecológica, a qual apresenta as seguintes vantagens, processo econômico, menor geração de gases de efeito de estufa, produção de energia, não utiliza compostos ácido/base concentrados como em outros processos, além disso, apresenta uma alta eficiência de remoção de metais, embora apresente como desvantagem um elevado tempo de operação e dependência de algumas condições atmosféricas.

Segundo Gonzaga et al. (2011), os mecanismos da biolixiviação são classificados de acordo a interação com o mineral. Na forma direta ocorre o ataque do mineral sulfeto por um sistema enzimático usando oxigênio e com liberação final de sulfato e cátions metálicos. O método indireto consiste no mecanismo de oxidação do mineral pelo Fe III, sendo papel dos microrganismos reoxidarem o ferro II em ferro III; usando duas espécies diferentes (tiossulfato e polissulfetos) de acordo com o tipo de sulfeto. A dissolução distingue dois tipos diferentes de sulfeto, de acordo com sua estrutura eletrônica e a combinação de orbitas de átomos de metais responsáveis por gerar a banda eletrônica, permitindo assim a valência de enxofre.

Outro aspecto importante é a determinação dos microrganismos utilizados no processo de biolixiviação para remoção de metais, os microrganismos sólidos utilizados são bactérias acidófilas e arquéias, sendo os mais importantes as Proteobactérias 
(Acidithiobacillus), Nitrospirae (Leptospirillum), Firmicutes (Alicyclobacillus) e Actinobacteria (Ferrimicrobium) (Fonti, Dell'anno \& Beolchini, 2016).

Atualmente, o bioleaching está sendo usado por muitos países produtores de metais como, por exemplo, o Chile teve a primeira operação comercial do mundo exclusivamente via sulfetos de cobre biolixiviantes, todas as operações de biolixivição realizadas no país contribuem cerca de $10 \%$ da produção total de cobre. Além disso, foi capaz de biolixiviar de maneira eficiente e econômica os recursos minerais difíceis de explorar por tecnologias tradicionais, como minerais sulfurados primários, calcopirita e bornita, permitindo assim extrair o cobre por meio de minerais sulfurados de baixo teor (Gentina \& Acevedo, 2016; Tanaka, 2017).

Segundo Christel et al. (2018), por consequência, o interesse industrial está aumentando constantemente e hoje cerca de 15 a $20 \%$ da produção mundial de cobre ocorre por meio do método de biolixiviação, portanto deve ser levado em consideração a produção sustentável de recursos minerais para o desenvolvimento econômico dos países. Dessa forma, a produção de metais valiosos a partir de minérios de baixa qualidade poderia ser produzida de maneira mais eficiente e comercialmente mais ampliado para o mundo.

O quadro 3 resume estudos focados na otimização da eficiência de remoção de diferentes metais e os microrganismos que levaram cada avaliação, para a recuperação de $\mathrm{Cu}(94 \%)$ a partir de resíduos de computador, avaliou a técnica de biolixiviação híbrida seguida da precipitação química como uma solução completa para a reciclagem de metais e recuperação de recursos do lixo eletrônico (Priya \& Hait, 2018). No seguinte exemplo, resíduos de esterco com adição de biocarvão teve uma recuperação de Cd (68-74\%) e Mn (77-79\%), este trabalho forneceu uma nova estratégia para acelerar o processo de biolixiviação e preservar os nutrientes (Wei et al., 2018).

Segundo Pereira et al. (2018), o tratamento de lodo de esgoto o $\mathrm{Zn}(76,5 \%)$ e Cr $(9,8 \%)$ alcançou concentrações máximas admissíveis pelas normas ambientais. Para o processamento de cinzas de incineradores de resíduos municipais a biolixiviação foi eficaz para $\mathrm{Nd}(76 \%)$ e $\mathrm{Pb}(59 \%)$ mostrando-se como uma técnica eficaz e mais seletiva em relação aos elementos tóxicos em comparação à lixiviação química (Funari et al., 2017). Por outro lado para a recuperação de Li (95\%) e Co $(96 \%)$ presentes nas baterias de íon de lítio, o porcentagem de recuperação dos metais valiosos foi elevada, sugerindo que o método de biolixiviação autotrófica é capaz de recuperar os metais de forma econômica (Xin et al., 2016).

Conclui-se que a biolixiviação é uma técnica promissora, sendo um processo ambientalmente seguro e eficiente na extração de metais, atuando em diferentes tipos de resíduos e mantendo uma alta eficiência do processo. Portanto, o sistema apresenta um potencial considerável para agregar valor ao setor de mineração e fornecer benefícios ambientais e sociais atraentes para todos os setores associados.

Quadro 3: Eficiência do processo de biolixiviação para remoção dos metais.

\begin{tabular}{|c|c|c|c|}
\hline Componente & Microrganismo & $\begin{array}{l}\text { Eficiência de lixiviação em } \\
\text { metais }(\%)\end{array}$ & Referências \\
\hline Resíduos do computador & $\begin{array}{l}\text { Acidithiobacillus } \\
\text { ferrooxidans }\end{array}$ & $\begin{array}{l}94 \% \text { do } \mathrm{Cu} \\
81 \% \text { do } \mathrm{Ni}\end{array}$ & Priya \& Hait, 2018 \\
\hline $\begin{array}{l}\text { Esterco com a adição de } \\
\text { biocarvão }\end{array}$ & $\begin{array}{l}\text { Clostridium } \\
\text { Alicyclobacillus }\end{array}$ & $\begin{array}{l}77-79 \% \text { do } \mathrm{Mn} \\
68-74 \% \text { do } \mathrm{Cd}\end{array}$ & Wei et al., 2018 \\
\hline Lodo de esgoto & $\begin{array}{l}\text { Acidithiobacillus } \\
\text { Meyerozyma guilliermondii }\end{array}$ & $\begin{array}{l}76,5 \% \text { do } \mathrm{Zn} \\
9.8 \% \text { do } \mathrm{Cr} \\
\end{array}$ & Pereira et al, 2018 \\
\hline $\begin{array}{l}\text { Cinzas de incineradores de } \\
\text { resíduos municipais }\end{array}$ & $\begin{array}{l}\text { At. ferrooxidans } L . \\
\text { ferrooxidans }\end{array}$ & $\begin{array}{l}76 \% \text { do } \mathrm{Nd} \\
59 \% \text { do } \mathrm{Pb}\end{array}$ & FunarI et al., 2017 \\
\hline Baterias de íon de lítio & $\begin{array}{l}\text { Acidithiobacillus } \\
\text { thiooxidans Leptospirillum } \\
\text { ferriphilum }\end{array}$ & $\begin{array}{l}95 \% \text { do } \mathrm{Li} \\
96 \% \text { do } \mathrm{Co}\end{array}$ & Xin et al., 2016 \\
\hline
\end{tabular}




\section{Comparação entre os diferentes métodos}

O Quadro 4 descreve as principais vantagens e desvantagens entre os diferentes métodos discutidos neste artigo para a remoção de metais de efluentes. Observa se as diferentes técnicas existentes para tratar metais de efluentes, sendo que cada uma delas apresenta seus prós e contras. Todos os métodos apresentados são interessantes para a remoção de íons metálicos, porém deve se identificar para cada metal o mais vantajoso.

Quadro 4: Vantagens, desvantagens e quais metais podem ser removidos pelos diferentes métodos para tratamento de águas residuais.

\begin{tabular}{|c|c|c|c|c|}
\hline Método & Vantagens & Desvantagens & Metais Removidos & Referência \\
\hline Adsorção & $\begin{array}{l}\text { Operação e projeto } \\
\text { simples, alta eficiência }\end{array}$ & $\begin{array}{l}\text { Adsorventes possuem } \\
\text { alto custo }\end{array}$ & $\begin{array}{l}\mathrm{Cr}, \mathrm{Pb}, \mathrm{Ni}, \mathrm{Cd}, \mathrm{Cu} \text { e } \\
\mathrm{Zn}\end{array}$ & Fu; Wang, 2011 \\
\hline Biossorção & $\begin{array}{l}\text { Baixo custo no processo, } \\
\text { menor quantidade } \\
\text { requerida de biossorvente, } \\
\text { baixa produção de } \\
\text { biomassa que necessita de } \\
\text { tratamento }\end{array}$ & $\begin{array}{l}\text { Cada metal necessita } \\
\text { de um biossorvente } \\
\text { diferente e controle } \\
\text { rigoroso de fatores } \\
\text { como } \\
\text { temperatura. }\end{array}$ & $\mathrm{Pb}^{2+}, \mathrm{Cd}^{2+}, \mathrm{Cu}$ e $\mathrm{Fe}$ & $\begin{array}{l}\text { He; Chen, } 2014 \\
\text { Michalak; Chojnacka; Witek- } \\
\text { Krowiak, } 2013\end{array}$ \\
\hline Eletrodiálise & $\begin{array}{l}\text { Baixo uso de agentes } \\
\text { químico, alta recuperação } \\
\text { do efluente }\end{array}$ & $\begin{array}{lr}\text { Altos custos } & \text { de } \\
\text { bombeamento } & \mathrm{e} \\
\text { manutenção } & \mathrm{de} \\
\text { membranas } & \end{array}$ & $\mathrm{Pb}^{2+}$ & Gherasim et al., 2014 \\
\hline Osmose Reversa & $\begin{array}{l}\text { Os custos operacionais são } \\
\text { médios, alta remoção de } \\
\text { metal, sem adição de } \\
\text { produtos químicos, } \\
\text { equipamento simples }\end{array}$ & $\begin{array}{l}\text { A membrana pode } \\
\text { sofrer ataque químico }\end{array}$ & $\mathrm{Cu}^{2+}, \mathrm{Ni}^{2+}, \mathrm{Zn}^{2+}$ e $\mathrm{Cr}$ & $\begin{array}{l}\text { Shahalam Am, Al-Harthy A, } \\
\text { Al-Zawhry, } 2002 \\
\text { Mierzwa, J.C, } 1996\end{array}$ \\
\hline Ultrafiltração & $\begin{array}{l}\text { Baixo custo operacional e } \\
\text { alta remoção de metais }\end{array}$ & $\begin{array}{l}\text { Muitas membranas } \\
\text { são suscetíveis ao } \\
\text { ataque químico, o } \\
\text { concentrado obtido } \\
\text { deve ser tratado ou } \\
\text { imobilizado, para } \\
\text { disposição final }\end{array}$ & $\begin{array}{l}\mathrm{Fe}(\mathrm{II}), \mathrm{Fe}(\mathrm{III}), \mathrm{Cu} \\
\text { (II) e } \mathrm{Cr} \text { (III) }\end{array}$ & $\begin{array}{l}\text { Mungray Aa, Kulkarni Sv, } \\
\text { Mungray Ak, } 2012 \\
\text { Mierzwa, J.C, } 1996\end{array}$ \\
\hline Precipitação química & $\begin{array}{l}\text { Operação de tratamento } \\
\text { simples }\end{array}$ & $\begin{array}{l}\text { Custo com disposição } \\
\text { de lodo, grande } \\
\text { quantidade de } \\
\text { produtos químicos }\end{array}$ & $\begin{array}{l}\mathrm{Cu}^{2+}, \mathrm{Zn}^{2+}, \mathrm{Cr}^{3+} \\
\mathrm{Pb}^{2+}, \mathrm{Cd}(\mathrm{II}), \mathrm{Mn} \text { (II) } \\
{\mathrm{e} \mathrm{Hg}^{2+}}\end{array}$ & Barakat, 2011 \\
\hline $\begin{array}{l}\text { Precipitação por } \\
\text { sulfeto }\end{array}$ & $\begin{array}{l}\text { Baixa solubilidade dos } \\
\text { sulfetos metálicos na } \\
\text { solução, remoção seletiva } \\
\text { de metais }\end{array}$ & $\begin{array}{lr}\text { Dificuldade } & \text { em } \\
\text { controlar } & \mathrm{a} \\
\text { concentração } & \text { de } \\
\text { sulfeto, pode } & \text { ocorrer } \\
\text { toxicidade } & \text { dos } \\
\text { microrganismos } & \mathrm{e} \\
\text { corrosão } & \end{array}$ & $\mathrm{Cu}, \mathrm{Pb}, \mathrm{Cd}, \mathrm{Zn}$ e $\mathrm{Ni}$ & Lewis, 2010 \\
\hline Biomineração & Baixo custo de energia & 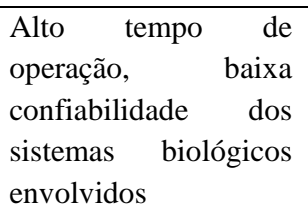 & $\mathrm{Cu}$ & Johnson, 2014 \\
\hline Biolixiviação & $\begin{array}{l}\text { Menos malefícios ao meio } \\
\text { ambiente, processo } \\
\text { econômico, alta eficiência }\end{array}$ & $\begin{array}{l}\text { Elevado tempo de } \\
\text { operação, depende de } \\
\text { condições } \\
\text { atmosféricas }\end{array}$ & $\begin{array}{l}\mathrm{Cu}, \mathrm{Zn}, \mathrm{Pb}, \mathrm{Ni}, \mathrm{Mn}, \\
\mathrm{Cd}, \mathrm{Fe}, \mathrm{Nd}, \mathrm{Co} \text { e Li }\end{array}$ & Asghari et al., 2013 \\
\hline
\end{tabular}

Fonte: Autores (2020). 
Analisando se os diversos métodos têm se que para a remoção de cromo pode se utilizar: adsorção, osmose reversa, ultrafiltração e precipitação química, sendo que tanto a adsorção quanto a precipitação química possuem alta eficiência na remoção deste metal, porém são métodos que possuem alto custo, desta forma, osmose reversa e ultrafiltração seriam mais viáveis, contudo como ponto negativo, ambos os processos utilizam membranas que são susceptíveis a ataques químicos.

Para o tratamento de chumbo tem se os processos de adsorção, biossorção, eletrodiálise, precipitação química, precipitação por sulfeto e biolixiviação, estes mesmos também são utilizados para o metal cádmio, exceto eletrodiálise. Todos estes possuem alta capacidade de remoção destes metais das águas residuais, mas a adsorção, precipitação química e eletrodiálise apresentam maior custo em relação aos outros métodos possíveis. Apesar de serem processos mais econômicos, na biossorção e na precipitação por sulfeto deve se ter um controle mais rigoroso dos fatores que interferem no processo e já a biolixiviação apresenta um maior tempo de operação.

Quando se deseja tratar níquel tem se a adsorção, osmose, precipitação por sulfeto e biolixiviação. Comparando estas técnicas entre si, tem se que a adsorção é o processo menos econômico.

A biossorção, ultrafiltração e biolixiviação conseguem remover metais como: ferro e cobre, sendo ainda para o cobre outros métodos possíveis: adsorção, osmose reversa, ultrafiltração, precipitação química e por sulfeto e biomineração, com exceção da biomineração estes também são processos capazes de extrair o zinco dos efluentes. De modo geral, na adsorção tem se alto custo com o adsorvente, na biossorção deve se controlar de modo efetivo parâmetros como temperatura e pH, na osmose e ultrafiltração é necessário se ter cuidados com a membrana utilizada, precipitação química se tem alto custo com a disposição do lodo gerado, na biomineração e biolixiviação se tem alto tempo de operação e na precipitação por sulfeto pode ocorrer corrosão e toxicidade dos microrganismos utilizados.

Para metais como mercúrio e manganês pode se utilizar a precipitação química e ainda para o manganês, neodímio, cobalto e lítio a biolixiviação.

Assim nota se que há muitas possibilidades para o tratamento de metais de efluentes, contudo, ainda os métodos mais utilizados atualmente são a precipitação química, precipitação por sulfeto, adsorção e ultrafiltração, destacando a biossorção que está sendo estudada como uma alternativa viável (De Freitas et al., 2019).

\section{Considerações Finais}

Os metais em altas concentrações são responsáveis por poluir os recursos hídricos presentes no meio ambiente, eles possuem características tóxicas que podem ser prejudiciais à saúde humana. Dessa forma, inúmeras técnicas foram discutidas com intuito de remover esses compostos de águas residuais, entre elas, a adsorção destaca-se por ser uma técnica eficaz, econômica, com um projeto simples e de fácil operação, contudo, o processo é altamente dependente do adsorvente, o carvão ativado é um dos materiais mais utilizados, porém é caracterizado pelo seu alto custo. Já a biossorção o adsorvente utilizado é de origem biológica, sendo, portanto, um método mais econômico e responsável por uma menor geração de lodo residual. Outra metodologia aplicada é a eletrodiálise a qual destaca-se por ser um procedimento eficiente para separar grandes volumes e concentrações relativamente baixas, o método utiliza-se uma pequena quantidade de substâncias químicas e muitas vezes uma recuperação satisfatória.

A osmose reversa também é mais utilizada em efluentes que possuem baixas concentrações de metais, o mecanismo funciona através de uma membrana seletiva, por isso não há utilização de produtos químicos. A técnica de ultrafiltração é caracterizada por ser uma técnica eficiente, ela baseia-se no processo de filtração através de uma membrana permeável, porém, o processo pode tornar-se inviável devido a ocorrência de incrustações nos poros. Entre as tecnologias mais empregadas, encontra-se a precipitação química, o tratamento caracteriza-se por ser um processo simples, eficiente e de baixo custo, no entanto, durante o processo há uma alta produção de lodo residual, o qual exige um tratamento e disposição adequada, além 
disso essa técnica utiliza-se uma quantidade acentuada de produtos químicos. Outro método é a precipitação por sulfeto, o qual destaca-se pela propriedade de baixa solubilidade dos sulfetos metálicos, isso facilita a remoção dos metais em solução de forma seletiva, apresentando-se como um procedimento de alto potencial.

A biomineração consiste em um método físico-químico que remove metais a partir de microrganismos em um meio adaptado, essa técnica é simples e econômica, porém é necessário um elevado tempo para que a remoção de metal ocorra de maneira eficiente. Na biolixiviação, os metais são removidos através de um processo de solubilização e posteriormente são extraídos a partir de microrganismos com características oxidantes, o método apresenta-se como uma tecnologia eficiente e econômica, porém apresenta um elevado tempo de operação e suscetibilidade às variações atmosféricas.

Por fim, evidencia-se a necessidade de estudos futuros quanto às técnicas supracitadas para que as técnicas de remoção de metais de águas residuárias sejam cada vez mais eficientes, de forma que o processo seja cada vez mais sustentável sob a ótica ambiental, econômica e social.

\section{Referências}

Abrão, A. (1994). Química e tecnologia das terras-raras. Série Tecnologia Mineral No66. CETEM/CNPQ, 212p.

Agustiono, T. et al. (2006). Physico - chemical treatment techniques for wastewater laden with heavy metals. Chemical Engineering Journal, 118, 83-98.

Al Duda \& Ward, T. (1995). The GEF and international Waters Our Planet, 7(4), 27-28.

Alvarez, M. T., Crespo, C. \& Mattiasson, B. (2007). Precipitation of $\mathrm{Zn}$ (II), Cu (II) and Pb (II) at bench-scale using biogenic hydrogen sulfide from the utilization of volatile fatty acids. Chemosphere, 66, 1677-1683.

Andrade, R. H. P. de. (2011). Terras raras. Sumário Mineral, DNPM - Departamento Nacional de Produção Mineral. 31, 89-90.

Asghari, I. et al. (2013). Journal of Industrial and Engineering Chemistry Bioleaching of spent refinery catalysts: A review. Journal of Industrial and Engineering Chemistry, 19(4), 1069-1081.

Baltpurvins, K.A. et al. (1997). Effect of electrolyte composition on zinc hydroxide precipitation by lime. Pergamon, 31(5), 973-980.

Barakat, M. A. (2011). New Trends In Removing Heavy Metals From Industrial Wastewater. Arabian Journal of Chemistry, 4, $361-377$.

Bisht, R. \& Agarwal, M. (2016). Heavy Metal Removal From Wastewater Using Various Adsorbents: A Review. Journal Of Water Reuse And Desalination, 7, 387-419.

Blue, L. Y. et al. (2008). Low-level mercury removal from groundwater using a synthetic chelating ligand. Water research, 42, $2025-2028$.

Brierley, C. L. (2008). How will biomining be applied in future? Transactions of Nonferrous Metals Society of China, 18(6), 1302-1310.

Burakov, A. E. et al. (2018). Ecotoxicology and Environmental Safety Adsorption of heavy metals on conventional and nanostructured materials for wastewater treatment purposes: A review. Ecotoxicology and Environmental Safety 148, 702-712.

Chang, J. S., Law, R. \& Chang, C. C. (1997). Biosorption of lead, copper and cadmium by biomass of Pseudomonas aeruginosa PU21. Water Research, 31(7), $1651-1658$

Chen, Q. et al. (2009). Precipitation of heavy metals from wastewater using simulated flue gas: Sequent additions of fly ash, lime and carbon dioxide. Water Research, 43, 2605-2614.

Christel, S.et al. (2018). Weak iron oxidation by Sulfobacillus thermosulfidooxidans maintains a favorable redox potential for chalcopyrite bioleaching. Frontiers in Microbiology, 9, 1-12.

De Freitas, G. R., Da Silva, M. G. C. \& Vieira, M. G. A. (2019). Biosorption technology for removal of toxic metals: a review of commercial biosorbents and patents. Environmental Science and Pollution Research, 26(19), 19097-19118.

Ebbers, B., Ottosen, L. M. \& Jensen, P. E. (2014). Comparison of two different electrodialytic cells for separation of phosphorus and heavy metals from sewage sludge ash. Chemosphere, 125, 122-129.

Fonti, V., Dell'anno, A. \& Beolchini, F. (2016). Does bioleaching represent a biotechnological strategy for remediation of contaminated sediments? Science of the Total Environment, 563-564, 302-319.

Fu, F. (2007). Effective removal of coordinated copper from wastewater using a new dithiocarbamate-type supramolecular heavy metal precipitant. Chemosphere, 69, 1783-1789.

Fu, F. \& Wang, Q. (2011). Removal of heavy metal ions from wastewaters: A review. Journal of Environmental Management, 92, 07-418. 
Funari, V. et al. (2017). Metal removal from Municipal Solid Waste Incineration fly ash: A comparison between chemical leaching and bioleaching. Waste Management, 60, 397-406.

Gentina, J. C. \& Acevedo, F. (2016). Copper bioleaching in Chile. Minerals, 6, 1.

Gherasim, C.-V., Křivčík, J., \& Mikulášek, P. (2014). Investigation of batch electrodialysis process for removal of lead ions from aqueous solutions. Chemical engineering Journal, 256, 324-334.

Ghosh, P., Samanta, A. N. \& Ray, S. (2011). Reduction of COD and removal of Zn $2+$ from rayon industry wastewater by combined electro-Fenton treatment and chemical precipitation. Desalination, 266, 213-217.

Gonzaga, S. S., Monteiro, O. D. \& Gomes, S. C. (2011). Biohydrometallurgical process: A pratical approach. Mechanisms of bioleaching - basic understanding and possible industrial applications. CETEM, 2011. Cap. 2, 24-26.

Gopalratnam, V. C, et al. (1998). "The Simultaneous Removal of Oil and Heavy Metals from Industrial Wastewater by Joint Precipitation and Air Flotation." Environ. Prog, 7-84.

Guimarães, L. S. (2011). Terras Raras e Sustentabilidade Energética, Defesanet.

Guo, Z. et al. (2006). Enhanced chromium recovery from tanning wastewater *. Journal of Cleaner Production, 14.

Ozaki, H, Sharma, K \& Saktaywin, W. (2002). Performance of an ultra-low-pressure reverse osmosis membrane (ULPROM) for separating heavy metal: effects of interference parameters. Desalination, 144 (1), 287-294.

Hadiani, M. R. et al. (2018). Biosorption of low concentration levels of Lead (II) and Cadmium (II) from aqueous solution by Saccharomyces cerevisiae: Response surface methodology. Biocatalysis and Agricultural Biotechnology, 15, 25-34.

He, J. \& Chen, J. P. (2014). A comprehensive review on biosorption of heavy metals by algal biomass: Materials, performances, chemistry, and modeling simulation tools. Bioresource Technology, 160, 67-78.

Hu, J. et al. (2009). Removal of chromium from aqueous solution by using oxidized multiwalled carbon nanotubes. Journal of Hazardous Materials, 162, $1542-1550$.

Huisman, J. L., Schouten, G. \& Schultz, C. (2006). Biologically produced sulphide for purification of process streams, effluent treatment and recovery of metals in the metal and mining industry. Hydrometallurgy, 83, 106-113.

Ipek U. 2005). Removal of Ni (II) and Zn (II) from an aqueous solution by reverse osmosis. Desalination, 174(2), 161-169.

Janyasuthiwong, S. et al. (2015). Effect of $\mathrm{pH}$ on $\mathrm{Cu}$, Ni and $\mathrm{Zn}$ removal by biogenic sulfide precipitation in an inversed fluidized bed bioreactor. Hydrometallurgy, 158, 94-100.

Johnson, D. B. (2014). Biomining_biotechnologies for extracting and recovering metals from ores and waste materials. Current Opinion in Biotechnology, $30,24-31$.

Josefa, M., Yabe, S. \& Oliveira, E. D.E. (2003). Heavy metals removal in industrial effluents by sequential adsorbent treatment. Advances in Environmental Research, 7, 263-272.

Khulbe, K.C; Matsuura, T. (2018). Removal of heavy metals and pollutants by membrane adsorption techniques. Applied Water Science, 8-19.

Lesmana, S. O. et al. (2009). Studies on potential applications of biomass for the separation of heavy metals from water and wastewater. Biochemical Engineering Journal, 44(1), 19-41.

Lewis, A. E. (2010). Review of metal sulphide precipitation. Hydrometallurgy, 104(2), 222-234.

Machemer, S. D. \& Wildeman, T. R. (1992). Adsorption compared with sulfide precipitation as metal removal processes from acid mine drainage in a constructed wetland. Journal of Contaminant Hydrology, 9(1-2), 115-131.

Mahmoud, A., \& Hoadley, A. F. A. (2012). An evaluation of a hybrid ion exchange electrodialysis process in the recovery of heavy metals from simulated dilute industrial wastewater. Water Research, 46(10), 3364-3376.

Michalak, I., Chojnacka, K. \& Witek-Krowiak, A. (2013). State of the art for the biosorption process - A review. Applied Biochemistry and Biotechnology, $170(6), 1389-1416$

Mohammadi, T. et al. (2005). Modeling of metal ion removal from wastewater by electrodialysis. Separation and Purification Technology, 41(1), 73-82.

Mohsen-Nia M., Montazeri P. \& Modarress H. (2007). Removal of $\mathrm{Cu} 2+$ and $\mathrm{Ni} 2+$ from wastewater with a chelating agent and reverse osmosis processes. $J$ Am Chem Soc., 217(1-3), 276-281.

Nascimento, D. N. O. et al. (2018). Biolixiviação De Minérios De Cobre Em Reatores Com Acidithiobacillus Ferrooxidans. Tecnologia em Metalurgia Materiais e Mineração, 15(2), 81-85.

Ozverdi, A. \& Erdem, M. (2006). Cu2+, Cd2+ and Pb2+ adsorption from aqueous solutions by pyrite and synthetic iron sulphide. Journal of Hazardous Materials, 137, 626-632.

Pang, F. M. et al. (2009). Heavy Metals Removal by Hydroxide Precipitation and Coagulation- Flocculation Methods from Aqueous Solutions. Water Qual. Res. J. Can., 44(2). 
Research, Society and Development, v. 11, n. 2, e5251126100, 2022

(CC BY 4.0) | ISSN 2525-3409 | DOI: http://dx.doi.org/10.33448/rsd-v11i2.26100

Pereira, F. et al. (2018). Bioleaching of toxic metals from sewage sludge by co-inoculation of Acidithiobacillus and the biosurfactant-producing yeast Meyerozyma guilliermondii. Journal of Environmental Management, 211, 28-35.

Priya, A. \& Hait, S. (2018). Hydrometallurgy Extraction of metals from high grade waste printed circuit board by conventional and hybrid bioleaching using Acidithiobacillus ferrooxidans. Hydrometallurgy, 177, 132-139.

Rawlings, D. E. \& Johnson, D. B. (2007). The microbiology of biomining: development and optimization of mineral-oxidizing microbial consortia. Microbiology, 153(2), 315-324.

Renu, Agarwal, M. \& Singh, K. (2016). Heavy metal removal from wastewater using various adsorbents: a review adsorbent: a review. Journal of Water Reuse and Desalination, 7, 387-419.

Roever, L. (2017). Compreendendo os estudos de revisão sistemática. Ver Soc Bras Clin Med., 15(2), 127-130.

Rosenberg, E. (2015). "Heavy Metals in Water: Presence, Removal and Safety”. Johnson Matthey Technol., 59, 293-297.

Rozaimah, S. et al. (1999). Removal of Mixed Heavy Metals by Hydroxide Precipitation. Jumal Kejunneraan, 11(2), 85-101.

Shahalam Am, Al-Harthy A, Al-Zawhry. (2002). A Feed water pretreatment in RO systems: unit processes in the Middle East. Desalination, 150(3), 235-245.

Shokoohi, R. et al. (2009). Biosorption of iron from aqueous solution by dried biomass of activated sludge. Journal of environmental health science and engineering, 6 (2), 107-114.

Strandberg, G. W., Shumate, S. E. \& Parrott, J. R. (1981). Microbial cells as biosorbents for heavy metals: Accumulation of uranium by Saccharomyces cerevisiae and Pseudomonas aeruginosa. Applied and Environmental Microbiology, 41(1), 237-245.

Tanaka, M. A. (2017). Comparison Study of Heap Bioleaching Sites in Chile and Finland for Further Development of Biotechnology for Mining. Kyushu University Institutional Repository, 4(4), 1-7.

Wang, H. et al. (2007). Mechanism Study on Adsorption Of Acidified Multiwalled Carbon Nanotubes To Pb (Ii). Journal Of Colloid And Interface Science, $316,277-283$.

WeI, X. et al. (2018). Science of the Total Environment Biochar addition for accelerating bioleaching of heavy metals from swine manure and reserving the nutrients. Science of the Total Environment, 631-632, 1553-1559.

Xin, Y. et al. (2016). Bioleaching of valuable metals Li, Co, Ni and Mn from spent electric vehicle Li-ion batteries for the purpose of recovery. Journal of Cleaner Production, 116, 249-258.

Yan, X. et al. (2017). Abiological Granular Sludge Formation Benefit for Heavy Metal Wastewater Treatment Using Sulfide Precipitation. Clean - Soil, Air, Water, 45(4), 2-9.

Ye, M. et al. (2017). Removal of metals from lead-zinc mine tailings using bioleaching and followed by sulfide precipitation. Chemosphere, 185, $1189-1196$.

Zhang, L.N. et al. (2009). Mechanism of combinationmembrane and electro-winning process on treatment and remediation of Cu2+ polluted water body. $J$ Environ Sci., 21(6), 764-769. 